\title{
Eksenel Yük Altındaki Lifli Polimer İle Sargılı Dairesel Enkesitli Kolonlarda Dayanım Azaltma Katsayısının İncelenmesi
}

\section{Analysis of Strength Reduction Factor for Axially-Loaded Circular Columns with Fiber Reinforced Polymer}

\author{
Aysun Tekin Özer 1 ${ }^{1}$, Sema Alacalı ${ }^{*} \mathbb{C}$ \\ 1,2 Yıldız Teknik Üniversitesi, İnșaat Fakültesi, İnșaat Mühendisliği Bölümü, İstanbul, TÜRKIYYE \\ Sorumlu Yazar / Corresponding Author*: semanoyal@gmail.com
}

Geliș Tarihi / Received: 02.11.2020

Kabul Tarihi / Accepted: 20.02.2021

Arastırma Makalesi/Research Article

Atıf șekli/ How to cite: ÖZER A.T., ALACALI S.(2021). Eksenel Yük Altındaki Lifli Polimer İle Sargılı Dairesel Enkesitli Kolonlarda Dayanım Azaltma Katsayısının İncelenmesi. DEÜFMD 23(69), 995-1004.

\section{Öz}

Yönetmeliklerde, yapısal tasarımda göz önüne alınan rasgele değişkenlerin belirsizliklerini hesaba katmak için dayanım azaltma katsayıları kullanılır. Bu amaçla, çalışma kapsamında literatürden elde edilen karbon lifli polimer (CFRP) ile sargllı, boyuna ve enine donatılı (dairesel etriye) ve donatısız eksenel yük etkisindeki kolon numuneleri için, hedef güvenilirlik indeksi $(\beta)$ ve performans fonksiyonunu oluşturan rasgele değişkenlere ilişskin farklı varyasyon katsayıları göz önüne alınarak ikinci moment yaklaşımına göre dayanım azaltma katsayıları $(\phi)$ hesaplanmıștır [1]. Hesaplamalarda, $\beta=3.5$ ve buna karşılık gelen göçme olasılığı değeri $p_{F}=2.33 * 10^{-4}$ olarak alınmıştır. ACI 318-19 yönetmeliğinde, eksenel yük etkisindeki donatısız kolonlar ve etriyeli kolonlar için dayanım azaltma katsayısının değerleri sırasıyla 0.60 ve 0.65 olarak önerilmiştir. Çalışma sonucunda lifli polimerle güçlendirilmiș kolonlar için ACI 318-19 yönetmeliğinde önerilen dayanım azaltma katsayısı değerleri, farklı varyasyon katsayıları için elde edilen dayanım azaltma katsayısı değerleri ile karşılaştırılmıştır.

Anahtar Kelimeler: Dayanım azaltma katsayısı, hedef güvenilirlik indeksi, lifli polimer, ikinci moment yaklaşımı, olasılıksal tasarim

\begin{abstract}
The code and regulations use strength reduction factors to take into account the uncertainties of the random variables considered in structural design. In this study, for plain concrete columns and reinforced concrete columns (tie-reinforced column) wrapped with carbon fiber polymer (CFRP) under axial load obtained from literature, the strength reduction factors $(\phi)$ were calculated according to second-order moment approach by taking into account the target reliability index $(\beta)$ and, different coefficient of variation of random variables of performance function [1]. In the calculations, the target reliability index was taken $\beta=3.5$ and the corresponding probability of failure as $p_{F}=2.33 * 10^{-4}$. In ACI 318-19, the strength reduction factors for plain column and tie-reinforced column under axial load are 0.60 and 0.65 , respectively. As a result of study, the strength reduction factors recommended in the ACI 318-19 for columns reinforced with fiber polymer were compared with the strength reduction factors obtained for different coefficient of variation.
\end{abstract}

Keywords: Strength reduction factor, target reliability, fiber polymer, second moment approach, probabilistic design 


\section{Giriş}

Günümüzde güçlendirme alanında yaygın kullanılan yöntemlerden biri taşıyıcı elemanların lifli polimer ile sargılanmasıdır. Lifli polimerlerin en büyük avantajlarl; yüksek dayanım kapasitesi, korozyon direnci, hafifliği ve uygulanmasının kolay olması olarak sıralanabilir. Lifli polimer ile sargılı kolonlarda eksenel yük kapasitesi, dayanım ve süneklik önemli ölçüde artmaktadır [2].

Mühendislik tasarımının temel özelliklerinden biri, ekonomik şartlar gözetilerek sistem güvenliğinin sağlanmasıdır. Bir yapının veya elemanın güvenilirliği, yapının veya söz konusu elemanın faydalı ömrü boyunca kullanım amaçlarını sürdürme olasılığı olarak tanımlanabilir. Yönetmeliklerde, bu güvenilirliği sağlamak amacıyla belirli güvenlik katsayıları kullanılır. Olasılıksal tasarımda ilgili güvenlik katsayıları, seçilen $\beta$ değerine bağlı olarak belirlenerek istenilen güvenlik düzeyine ulaşmaya çalışılır. Güvenilirlik veya göçme olasılığının, güvenlik katsayısının belirlenmesinde göz önüne alınan riske eșdeğer olduğu kabul edilir.

ACI 318'de, yapı elemanlarının güvenilirliği, hesaplanan dayanım değerlerinin birden küçük $\phi$ katsayısı ile çarpılarak azaltılması ile sağlanmaktadır. $\quad \phi \quad$ katsayısı, elemanda kullanılan malzemenin boyut ve dayanımındaki belirsizlikleri hesaba katmak, tasarım denklemlerindeki olası hataları azaltmak ve elemanın yapı için önemini dikkate almak amacıyla kullanılır.

Yönetmeliklerde $\phi$ katsayıları belirli bir $\beta$ indeksi göz önüne alınarak belirlenir. Bu değer yapısal tasarımda kabul edilen göçme riskine bağlı değişir. Göçme riski ya da göçme olasılığı ise göçme nedeniyle oluşabilecek can kaybı sayısı ve zarar maliyetine göre tahmin edilir. Literatürde yapılan araştırmalarda çalışmanın konusunu oluşturan lifli polimer ile sargilı beton elemanlarıyla ilgili yapılan çalışmalarda $\beta$ indeksinin değeri Zou ve Hong [3], Alqam ve diğ. [4] ve Yingwu ve diğ. [5] tarafından 3.5 olarak kabul edilmiştir. Mirza'nın, enine sargılı betonarme kolonlarla ilgili yaptığı çalıșmada güvenilirlik indeksi 3.0-3.5 arasında önerilmiștir [6]. Bu çalıșmada ise ACI 318-19 yönetmeliğine göre $\phi$ katsayısının belirlenmesinde $\beta$ indeksi 3.5 ve bu değere karşılık gelen göçme olasılığı $p_{F}=2.33 * 10^{-4}$ olarak kabul edilmiştir.
Literatürde $\phi$ katsayısının bulunmasına yönelik olarak betonarme kiriș elemanların kesme ve eğilme dayanımlarının belirlenmesiyle ilgili bazı çalışmalar mevcuttur. Bu çalışmalardan, enine donatılı betonarme kirişlerin kesme dayanımının belirlenmesinde ACI 318-02 ve ACI 318-11 yönetmeliklerinde öngörülen $\phi=0.75$ değerinin betona ilișkin varyasyon katsayısı $V_{f_{c}}=0.10$ ve $p_{F}=10^{-5} \quad(\beta=4.27)$ göçme olasılığına, ACI 318-95'de önerilen $\phi=0.85$ değerinin ise betona ilişkin varyasyon katsayısı $V_{f_{c}}=0.10 \quad$ ve $p_{F}=10^{-2} \quad(\beta=2.33)$ göçme olasılığına karșılık geldiği görülmüștür [7]. Enine donatısız betonarme kirişlerin kesme dayanımı ile ilgili olarak yapılan çalışmada da, ACI 318-95'de önerilen $\phi=0.85$ değerinin betona ilişkin varyasyon katsayısı $V_{f_{c}}=0.12$ ve $p_{F}=10^{-5}$ göçme olasılığına, ACI 318-11'de önerilen $\phi=0.75$ değerinin ise betona ilişkin varyasyon katsayısı $V_{f_{c}}=0.18$ ve $p_{F}=10^{-5}$ $(\beta=4.27)$ göçme olasılığına karşılık geldiği görülmüștür [8].

Ayrıca betonarme kirişlerin eğilme momenti kapasitesinin belirlenmesiyle ilgili olarak yapılan çalışmada ACI 318-02 ve ACI 318-11'de önerilen $\phi=0.90 \quad$ değerinin $\quad \beta=3.5$ $\left(p_{F}=2.33 * 10^{-4}\right)$ için, sırasıyla donatı akma ve beton basınç dayanımlarının $V_{f_{y}}=0.03$ ve $V_{f_{c}}=0.05$ varyasyon katsayılarına karşılık geldiği görülmüştür [9].

Eksenel basınç etkisindeki kolonlarla ilgili olarak ACI 318 yönetmeliğinde $\phi$ katsayısının değeri donatısız ve enine donatının etriyeli ve spiral olması durumları için farklılık göstermektedir. ACI 318-05'de eksenel basınç etkisindeki spiral donatılı betonarme kolonlarda $\phi$ katsayısı 0.70 , diğer donatılı betonarme kolonlarda 0.65 ve donatısız kolonlarda 0.65 olarak önerilmiştir [10].

ACI $318-14$ ve ACI $318-19$ 'da $\phi$ katsayıları, spiral donatılı betonarme kolonlarda 0.75 , diğer donatılı betonarme kolonlarda 0.65 ve donatısız kolonlarda 0.60 olarak önerilmiştir $[11,12]$.

ACI 440.2R-17 yönetmeliğinde ise lifli polimer ile sargılı spiral ve diğer donatılı ve donatısız kolonların eksenel basınç dayanımının belirlenmesiyle ilgili bir katsayı önerilmemiş ve tasarımda ACI 318'in öngördüğü $\phi$ katsayılarının geçerli olduğu vurgulanmıştır [13]. 
DEÜ FMD 23(69), 995-1004, 2021

$\mathrm{Bu}$ çalıșmada, literatürden elde edilen lifli polimer ile sargilı enine (dairesel etriyeli) ve boyuna donatılı ve donatısız kolonlarda birinci derece ikinci-moment yaklaşımı kullanılarak rasgele değişkenlerin farklı varyasyon katsayısı değerleri için $\phi$ katsayıları hesaplanmış ve ACI 318-19'da önerilen $\phi$ değerleri ile karşılaștırılmıştır.

Olasılıksal hesaplarda rasgele değișkenlerin kendine özgü dağılımları dikkate alınmış, değișkenler arasındaki korelasyon etkisi ihmal edilerek değișkenlerin istatistiksel bağımsız oldukları varsayılmıștır.

\section{Lifli Polimer (FRP) ile sargılı kolonların tasarımı}

ACI 318-19'a göre eksenel yüklü kolonlarda $P_{n}$ nominal yük değeri birden küçük $\phi$ katsayısı ile çarpılarak azaltılır. (1) bağıntısına göre azaltılmış nominal dayanımın $P_{u}$ son limit yüklerini karşıladığı gösterilerek güvenlik sağlanmaya çalışılır.

$$
\phi P_{n} \geq P_{u}
$$

Lifli polimer ile sargıll, spiral veya etriyeli kolonlarda eksenel yük tașıma gücü, ACI 440.2R-17 yönetmeliğine göre aşağıdaki bağıntılar ile hesaplanır. Taşıma gücü bağıntılarında spiral veya etriye yanal donatılarının taşıma gücüne katkısı dikkate alınmamıștır.

Spiral donatı kullanıldığı durumlarda;

$$
\phi P_{n}=0.85 \phi\left[0.85 f_{c c}^{\prime}\left(A_{g}-A_{s t}\right)+f_{y} A_{s t}\right]
$$

Etriye kullanıldığı durumlarda;

$$
\phi P_{n}=0.80 \phi\left[0.85 f_{c c}^{\prime}\left(A_{g}-A_{s t}\right)+f_{y} A_{s t}\right]
$$

Burada $f_{c c}^{\prime}$, sargılı betonun basınç dayanımını; $A_{g}$, kolon enkesit alanını; $A_{s t}$, boyuna donatı alanını; $f_{y}$, boyuna donatı akma dayanımını; $\phi$, dayanım azaltma katsayısını ve $P_{n}$, nominal eksenel basınç dayanımını göstermektedir.

Sargılı betonun basınç dayanımı $f_{c c}^{\prime}$ ve FRP (lifli polimer) sargılama basıncı $f_{l}$ așağıda belirtilen (4) ve (5) bağıntıları ile bulunur [13].

$$
\begin{gathered}
f_{c c}^{\prime}=f_{c}^{\prime}+\psi_{f} 3.3 \kappa_{\mathrm{a}} f_{l} \\
f_{l}=\frac{2 n t_{f} E_{f} \varepsilon_{f e}}{D}
\end{gathered}
$$

(4) bağıntısında $\psi_{f}$ ek azaltma katsayısı olarak tanımlanmış ve değeri $0.95, \kappa_{\mathrm{a}}$ ise şekil etkinlik katsayısı olup yönetmelikte dairesel kolonlar için bu değer 1 olarak önerilmiştir. (5) bağıntısında ise $n$, tek yüzeydeki FRP sargı tabaka sayısını; $t_{f}$, bir tabaka FRP için etkili kalınlığı; $E_{f}$, FRP malzemesinin elastisite modülünü; $\varepsilon_{f e}$, etkin șekil değiștirme değerini; $D$, kolon enkesit çapını göstermektedir.

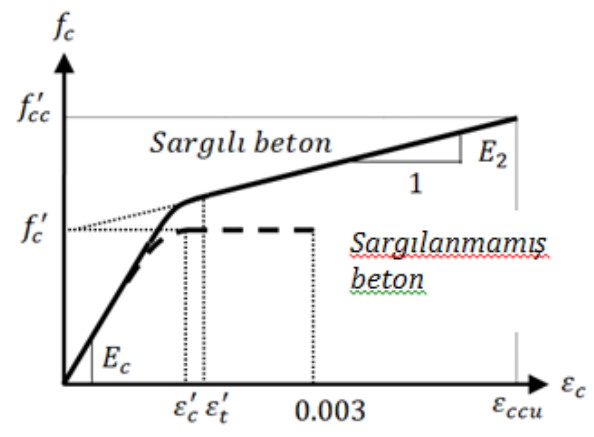

Şekil 1. Lam ve Teng'e göre FRP ile sargılı betonun gerilme-șekil değiștirme ilişkisi [13]

ACI 440.2R-17 yönetmeliğinde, lifli polimer ile sargılı betonun gerilme şekil değiștirme ilişkisinde Lam ve Teng'in önerdiği model esas alınmıştır (Şekil 1). Bu modele göre $f_{c}^{\prime}$ ve $f_{c c}^{\prime}$ sırasıyla sargılanmamıș ve sargilı betonun basınç dayanımını, $E_{c}$ betonun elastisite modülünü, $\varepsilon_{c}^{\prime}, \varepsilon_{t}^{\prime}$ ve $E_{2}$ sirasiyla $f_{c}^{\prime}$ değerine karşılık gelen birim şekil değiştirmeyi, eğrinin lineer bölgeye geçiş noktasındaki birim şekil değiștirmeyi ve lineer kısmın eğimini ifade etmektedir. Bu modele göre lifli polimer ile sargılı betonun maksimum şekil değiștirme oranı $\varepsilon_{c c u}$ (6) bağıntısı ile hesaplanır. Bu bağıntıda yer alan $f_{l} / f_{c}^{\prime}$ oranı 0.08 den küçük olmamalıdır. Ayrıca (6) bağıntısı ile hesaplanan $\varepsilon_{c c u}$ değeri aşırı çatlamayı ve bundan kaynaklı beton bütünlüğü kaybını önlemek amacıyla (7) bağıntısı ile gösterilen değerden küçük olmalıdır. 


$$
\begin{gathered}
\varepsilon_{c c u}=\varepsilon_{c}^{\prime}\left[1.50+12 \kappa_{\mathrm{b}} \frac{f_{l}}{f_{c}^{\prime}}\left(\frac{\varepsilon_{f e}}{\varepsilon_{c}^{\prime}}\right)^{0.45}\right] \\
\varepsilon_{c c u} \leq 0.01
\end{gathered}
$$

(6) bağıntısında $\kappa_{b}$ şekil etkinlik katsayısı olarak tanımlanmakta ve ACI 318-19'a göre dairesel enkesitli kolonlar için bu değer 1 olarak önerilmektedir.

\section{Güvenilirlik Analizi}

\subsection{Kısmi güvenlik katsayılarının bulunması}

Olasılıksal tasarımda bir sistemin davranıșı performans fonksiyonu olarak adlandırılan aşağıdaki bağıntı ile tanımlanabilir.

$$
Z=g(x)=g\left(X_{1}, X_{2}, \ldots X_{n}\right)
$$

$Z=0$ durumu limit durumu, $Z<0$ göçme durumunu ve $Z>0$ güvenli durumu ifade eder. İndirgenmiş değişkenler uzayında farklı göçme yüzeylerine karşılık gelen tasarımlar Şekil 2'de gösterilmiștir.

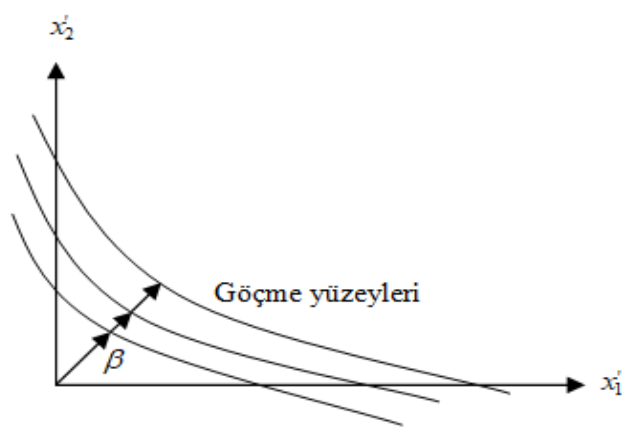

Şekil 2. Farklı göçme yüzeylerine karşılık gelen tasarımlar [14]

$\mathrm{Bu}$ durumda performans fonksiyonu, (9) bağıntısında gösterildiği gibi her bir değișkenin kısmi güvenlik katsayısı ile çarpılması ile elde edilir.

$$
g\left(\gamma_{1} m_{x_{1}}, \gamma_{2} m_{x_{2}}, \ldots \ldots \gamma_{n} m_{x_{n}}\right)=0
$$

Burada $\gamma_{i} m_{x_{i}}$ göçme yüzeyi üzerinde bulunan en olası göçme noktasıdır. $\mathrm{Bu}$ nedenle $x_{i}^{*}=\gamma_{i} m_{x_{i}}$ olacaktır. Buna göre kısmı güvenlik katsayısı (10) bağıntısı ile hesaplanabilir.

$$
\gamma_{i}=\frac{x_{i}^{*}}{m_{x_{i}}}
$$

İndirgenmiş değișkenler uzayında en olası göçme noktası $x_{i}^{*}=-\alpha_{i}^{*} \beta$ dır. $\mathrm{Bu}$ bağıntıda duyarlılık katsayısı olarak ifade edilen $\alpha_{i}^{*}$ (11) bağıntısı ile belirlenir [14].

$$
\alpha_{i}^{*}=\left(\frac{\partial g}{\partial X_{i}}\right)_{*} /\left[\sum_{i=1}^{n}\left(\frac{\partial g}{\partial X_{i}}\right)_{*}^{2}\right]^{\frac{1}{2}}
$$

Orijinal değişkenler aşağıdaki bağıntıyla ifade edilirse;

$$
x_{i}^{*}=m_{x_{i}}-\alpha_{i}^{*} \beta \sigma_{x_{i}}=m_{x_{i}}\left(1-\alpha_{i}^{*} \beta V_{x_{i}}\right)
$$

$\mathrm{Bu}$ bağıntıda $\sigma_{x_{i}}$ ve $V_{x_{i}} \quad\left(=\sigma_{x_{i}} / m_{x_{i}}\right)$ sirasıyla $X_{i}$ rasgele değişkeninin standart sapma ve varyasyon katsayısı değerlerini ifade etmektedir. Kısmi güvenlik katsayıları (13) bağıntısı ile hesaplanır.

$$
\gamma_{i}=\frac{x_{i}^{*}}{m_{x_{i}}}=1-\alpha_{i}^{*} \beta V_{x_{i}}
$$

\subsection{Performans fonksiyonunun}

\section{oluşturulması}

Eksenel yüklü kolonlar için performans fonksiyonu aşağıdaki bağıntıyla hesaplanır.

$$
g(x)=\gamma_{1} P_{n}-\gamma_{2} P_{u}=\phi P_{n}-P_{u}
$$

Bu bağıntıda, $P_{u}$ deneysel verilerden elde edilen eksenel basınç dayanımlarını, $P_{n}$ ACI'ya göre hesaplanan eksenel basınç dayanımlarını, $\gamma_{1}$ ve $\gamma_{2}$ ise, $\beta$ değerine karşılık gelen ilgili değişkenlerin güvenlik katsayılarını ifade etmektedir. Bu çalışmada olasılıksal hesaplar sonucu belirlenen $\gamma_{1}$ güvenlik katsayısının $\phi$ değerine karşılık geldiği varsayılmıștır. Belirlemelerde $\beta=3.5$ ve bu değere karşıllk gelen göçme olasılığ $\quad p_{F}=2.33 * 10^{-4} \quad$ olarak alınmıştır.

(3) bağıntısında gerekli düzenlemeler yapılırsa, lifli polimer ile sargıll, enine ve boyuna donatılı kolonlar için performans fonksiyonu (15), donatısız kolonlar için ise (16) bağıntısıyla tanımlanabilir [13]. 
DEÜ FMD 23(69), 995-1004, 2021

$$
\begin{gathered}
g(X)=\phi\left[\begin{array}{c}
0.85\left(f_{c}^{\prime}+\frac{3.49 n t_{f} E_{f} \varepsilon_{f u}}{D}\right) \\
\left(\frac{\pi D^{2}}{4}-\frac{\rho_{g} \pi D^{2}}{4}\right)+f_{y} \frac{\rho_{g} \pi D^{2}}{4}
\end{array}\right]-P_{u} \\
g(X)=\phi\left[0.85\left(f_{c}^{\prime}+\frac{3.49 n t_{f} E_{f} \varepsilon_{f u}}{D}\right) \frac{\pi D^{2}}{4}\right]-P_{u}
\end{gathered}
$$

(15) ve (16) bağıntılarındaki; $f_{c}^{\prime}$, sargılanmamıș betonun basınç dayanımını; $n . t_{f}$, lifli polimerin toplam etkili sargı kalınlığını; $E_{f}$, lifli polimerin elastisite modülünü; $\varepsilon_{f u}$, lifli polimerin kopma birim uzamasını; $f_{y}$, boyuna donatı akma dayanımını; $\rho_{g}$, boyuna donatı oranını; $P_{u}$, son limit yükünü ve $\phi$ dayanım azaltma katsayısını göstermektedir.

\subsection{Değişkenlerin varyasyon katsayıları}

$\mathrm{Bu}$ çalışmada performans fonksiyonlarını oluşturan rasgele değişkenlere ilişkin varyasyon katsayıları literatürdeki çalışmalar esas alınarak Tablo 1 ve 2'de özetlenmiştir [15-28].

Söz konusu değişkenlerin dağılım tipleri ise değişkenin yapısına uygun olarak normal, lognormal ve Tip-I asimptotik dağılım olarak kabul edilmiștir (Tablo 1-2).

Tablo 1. Lifli polimer ile sargill, enine ve boyuna donatılı kolonlara ilişkin varyasyon

\begin{tabular}{|c|c|c|c|c|c|c|c|c|c|}
\hline Durum & $f_{c}^{\prime}$ & $E_{f}$ & $t_{f}$ & \multirow[t]{2}{*}{$f_{y}$} & $\varepsilon_{f u}$ & $\rho_{g}$ & $D$ & $P_{u}$ & $\phi$ \\
\hline 1 & \multirow{6}{*}{0.10} & \multirow{2}{*}{0.10} & 0.05 & & & & & & 0.756 \\
\hline 2 & & & 0.07 & & & & & & 0.752 \\
\hline 3 & & 015 & 0.05 & & & & & & 0.738 \\
\hline 4 & & 0.15 & 0.07 & & & & & & 0.735 \\
\hline 5 & & & 0.05 & & & & & & 0.720 \\
\hline 6 & & 0.20 & 0.07 & & & & & & 0.718 \\
\hline 7 & & & 0.05 & & & & & & 0.737 \\
\hline 8 & & 0.10 & 0.07 & & & & & & 0.733 \\
\hline 9 & 012 & 015 & 0.05 & & & & & & 0.719 \\
\hline 10 & 0.12 & 0.15 & 0.07 & & & & & & 0.716 \\
\hline 11 & & & 0.05 & & & & & & 0.701 \\
\hline 12 & & 0.20 & 0.07 & 윽 & $\underset{N}{N}$ & 으 & $m$ & 5 & 0.699 \\
\hline 13 & & & 0.05 & "̆ & $\stackrel{0}{\circ}$ & $\ddot{0}$ & $\stackrel{0}{0}$ & $\stackrel{\circ}{0}$ & 0.708 \\
\hline 14 & & 0.10 & 0.07 & & & & & & 0.704 \\
\hline 15 & 015 & & 0.05 & & & & & & 0.691 \\
\hline 16 & 0.15 & 0.15 & 0.07 & & & & & & 0.688 \\
\hline 17 & & & 0.05 & & & & & & 0.673 \\
\hline 18 & & 0.20 & 0.07 & & & & & & 0.671 \\
\hline 19 & & 010 & 0.05 & & & & & & 0.680 \\
\hline 20 & & 0.10 & 0.07 & & & & & & 0.676 \\
\hline 21 & 018 & 015 & 0.05 & & & & & & 0.663 \\
\hline 22 & 0.18 & 0.15 & 0.07 & & & & & & 0.660 \\
\hline 23 & & & 0.05 & & & & & & 0.646 \\
\hline 24 & & 0.20 & 0.07 & & & & & & 0.644 \\
\hline $\begin{array}{c}\text { Dağılım } \\
\text { Tipi }\end{array}$ & LN & LN & $\mathrm{N}$ & LN & $\mathrm{T}$ & $\mathrm{N}$ & $\mathrm{N}$ & $\mathrm{T}$ & \\
\hline
\end{tabular}
katsayıları ve dağılım tipleri
Tablo 2. Lifli polimer ile sargilı, enine ve boyuna donatısız kolonlara ilișkin varyasyon

\begin{tabular}{|c|c|c|c|c|c|c|c|}
\hline Durum & $f_{c}^{\prime}$ & $E_{f}$ & $t_{f}$ & $\varepsilon_{f u}$ & $D$ & $P_{u}$ & $\phi$ \\
\hline 1 & \multirow{6}{*}{0.10} & \multirow{2}{*}{0.10} & 0.05 & \multirow{24}{*}{$\begin{array}{l}\text { Ñ} \\
0 \\
0\end{array}$} & \multirow{24}{*}{$\stackrel{\text { ஜூ }}{\circ}$} & \multirow{24}{*}{ ర્' } & 0.745 \\
\hline 2 & & & 0.07 & & & & 0.740 \\
\hline 3 & & \multirow{2}{*}{0.15} & 0.05 & & & & 0.723 \\
\hline 4 & & & 0.07 & & & & 0.719 \\
\hline 5 & & \multirow{2}{*}{0.20} & 0.05 & & & & 0.701 \\
\hline 6 & & & 0.07 & & & & 0.698 \\
\hline 7 & \multirow{6}{*}{0.12} & \multirow{2}{*}{0.10} & 0.05 & & & & 0.720 \\
\hline 8 & & & 0.07 & & & & 0.715 \\
\hline 9 & & 015 & 0.05 & & & & 0.698 \\
\hline 10 & & 0.15 & 0.07 & & & & 0.695 \\
\hline 11 & & 020 & 0.05 & & & & 0.676 \\
\hline 12 & & 0.20 & 0.07 & & & & 0.674 \\
\hline 13 & \multirow{6}{*}{0.15} & \multirow{2}{*}{0.10} & 0.05 & & & & 0.683 \\
\hline 14 & & & 0.07 & & & & 0.678 \\
\hline 15 & & \multirow{2}{*}{0.15} & 0.05 & & & & 0.662 \\
\hline 16 & & & 0.07 & & & & 0.659 \\
\hline 17 & & \multirow{2}{*}{0.20} & 0.05 & & & & 0.641 \\
\hline 18 & & & 0.07 & & & & 0.638 \\
\hline 19 & \multirow{6}{*}{0.18} & \multirow{2}{*}{0.10} & 0.05 & & & & 0.647 \\
\hline 20 & & & 0.07 & & & & 0.643 \\
\hline 21 & & \multirow{2}{*}{0.15} & 0.05 & & & & 0.627 \\
\hline 22 & & & 0.07 & & & & 0.624 \\
\hline 23 & & \multirow{2}{*}{0.20} & 0.05 & & & & 0.606 \\
\hline 24 & & & 0.07 & & & & 0.604 \\
\hline $\begin{array}{c}\text { Dağılım } \\
\text { Tipi }\end{array}$ & LN & LN & $\mathrm{N}$ & $\mathrm{T}$ & $\mathrm{N}$ & $\mathrm{T}$ & \\
\hline
\end{tabular}
katsayıları ve dağılım tipleri

\section{Kolon Numunelerinin Özellikleri}

Lifli polimer ile sargılı, enine ve boyuna donatılı eksenel yüklü dairesel kolonlarda $\phi$ katsayıları literatürdeki 4 farklı çalışmadan elde edilen 21 adet deney numunesi göz önüne alınarak hesaplanmiștır [29-32]. Numuneler kumaș şeklinde lifli polimerle sargılı ve enine donatı olarak dairesel etriye kullanılmıştır. Kolon enkesit çapı $D, 150-250 \mathrm{~mm}$; sargılanmamıș betonun basınç dayanımı $f_{c}^{\prime}, 12.84-63.01 \mathrm{MPa}$; $f_{y}$, boyuna donatı akma dayanımı 367-587 MPa; $n . t_{f}$, lifli polimerin toplam etkili sargı kalınlığ 0.130-0.825 $\mathrm{mm} ; E_{f}$, lifli polimerin elastisite modülü 217-241 GPa; $\rho_{g}$, boyuna donatı oranı 0.0096-0.0225; $\varepsilon_{f u}$, lifli polimerin kopma birim uzaması $0.0144-0.018 \mathrm{~mm} / \mathrm{mm}$ arasında değişmektedir (Tablo 3).

Lifli polimer ile sargill, enine ve boyuna donatısız eksenel yüklü dairesel beton kolonlarda ise $\phi$ katsayısı, 2 farklı çalışmadan alınan 38 adet deney numunesi göz önüne 
DEÜ FMD 23(69), 995-1004, 2021

alınarak hesaplanmıștır [33-34]. Numuneler kumaş şeklinde lifli polimerle sargllı ve kolonlarda enine ve boyuna donatı kullanılmamıștır. Kolon enkesit çapı $D$, 100-200 $\mathrm{mm}$; sargılanmamış betonun basınç dayanımı $f_{c}^{\prime}, 17.05-47.5 \mathrm{MPa}$; $n . t_{f}$, lifli polimerin toplam etkili sargı kalınlığı $0.11-0.351 \mathrm{~mm}, E_{f}$, lifli polimerin elastisite modülü $232-240 \mathrm{GPa} ; \varepsilon_{f u}$, lifli polimerin kopma birim uzaması 0.0155 $0.018 \mathrm{~mm} / \mathrm{mm}$ değerleri arasında değişmektedir (Tablo 4).

Tablo 3. Lifli polimer ile sargıll, enine ve boyuna donatılı kolon numunelerinin özellikleri

\begin{tabular}{|llcccccccc|}
\hline Makale & $\begin{array}{l}\text { Numune } \\
\text { Adl }\end{array}$ & $\begin{array}{c}D \\
(\mathrm{~mm})\end{array}$ & $\begin{array}{c}f_{c}^{\prime} \\
(\mathrm{MPa})\end{array}$ & $\begin{array}{c}f_{y} \\
(\mathrm{MPa})\end{array}$ & $\rho_{g}$ & $\begin{array}{c}\mathrm{n} . t_{f} \\
(\mathrm{~mm})\end{array}$ & $\begin{array}{c}E_{f} \\
(\mathrm{GPa})\end{array}$ & $\begin{array}{c}\varepsilon_{f u} \\
(\mathrm{~mm} / \mathrm{mm})\end{array}$ & $\begin{array}{c}P_{u} \\
(\mathrm{kN})\end{array}$ \\
\hline Chastre & C10 & 150 & 38.00 & 391 & 0.0096 & 0.334 & 226 & 0.0144 & 1485.70 \\
ve & C11 & 150 & 38.00 & 391 & 0.0096 & 0.334 & 226 & 0.0144 & 1375.80 \\
Silva [29] & C15 & 150 & 38.00 & 391 & 0.0096 & 0.334 & 226 & 0.0144 & 1480.90 \\
& C19 & 150 & 38.00 & 391 & 0.0096 & 0.334 & 226 & 0.0144 & 1492.30 \\
& C41 & 250 & 35.20 & 458 & 0.0138 & 0.167 & 241 & 0.0154 & 2766.70 \\
& C34 & 250 & 35.20 & 458 & 0.0138 & 0.334 & 241 & 0.0154 & 3741.60 \\
& C43 & 250 & 35.20 & 458 & 0.0138 & 0.501 & 241 & 0.0154 & 3966.80 \\
& C44 & 250 & 35.20 & 458 & 0.0138 & 0.668 & 241 & 0.0154 & 4828.30 \\
\hline Benzaid & I.RCC-1L & 160 & 29.51 & 500 & 0.0225 & 0.130 & 238 & 0.0180 & 1206.53 \\
ve & I.RCC-3L & 160 & 29.51 & 500 & 0.0225 & 0.390 & 238 & 0.0180 & 1628.49 \\
Mesbah & II.RCC-3L & 160 & 58.24 & 500 & 0.0225 & 0.390 & 238 & 0.0180 & 2199.63 \\
{$[30]$} & III.RCC-3L & 160 & 63.01 & 500 & 0.0225 & 0.390 & 238 & 0.0180 & 2089.57 \\
\hline Faustino & CC1 & 150 & 34.60 & 587 & 0.0128 & 0.352 & 217 & 0.0155 & 1838.00 \\
ve & CC2 & 150 & 34.60 & 587 & 0.0128 & 0.352 & 217 & 0.0155 & 1843.00 \\
diğ. [31] & CC3 & 150 & 34.60 & 587 & 0.0128 & 0.352 & 217 & 0.0155 & 1804.00 \\
\hline Peker [32] & LSR-C-1-a & 250 & 12.84 & 367 & 0.0096 & 0.165 & 230 & 0.0150 & 1584.76 \\
& LSR-C-1-b & 250 & 13.14 & 367 & 0.0096 & 0.165 & 230 & 0.0150 & 1663.52 \\
& LSR-C-3-a & 250 & 12.84 & 367 & 0.0096 & 0.495 & 230 & 0.0150 & 2901.28 \\
& LSR-C-3-b & 250 & 13.14 & 367 & 0.0096 & 0.495 & 230 & 0.0150 & 3091.86 \\
& LSR-C-5-a & 250 & 12.84 & 367 & 0.0096 & 0.825 & 230 & 0.0150 & 4299.48 \\
& LSR-C-5-b & 250 & 13.53 & 367 & 0.0096 & 0.825 & 230 & 0.0150 & 4675.29 \\
\hline
\end{tabular}

\section{Rasgele Değișkenlerdeki Belirsizliklerin $\phi$ Üzerindeki Etkisi}

Lifli polimer ile sargılı, enine ve boyuna donatılı kolonlarda $\phi$ katsayısının belirlenmesine yönelik yapılan olasılıksal hesaplamalar sonucunda ACI 318-19'da etriyeli kolonlar için önerilen $\phi=0.65$ değerinin, $\beta=3.5$ için, değişkenlerin varyasyon katsayılarının $V_{f_{c}^{\prime}}=$ 0.18, $V_{t_{f}}=0.05, V_{E_{f}}=0.20, V_{\varepsilon_{f u}}=0.022, V_{D}=$ $0.03, V_{\rho_{g}}=0.10$ ve $V_{f_{y}}=0.10$ olduğu 23 nolu duruma karşılık geldiği görülmüştür. Enine ve boyuna donatısız kolonlar için ise ACI 318-19'da önerilen $\phi=0.60$ değerinin varyasyon katsayılarının $\quad V_{f_{c}^{\prime}}=0.18, \quad V_{t_{f}}=0.07, \quad V_{E_{f}}=$ $0.20, V_{\varepsilon_{f u}}=0.022$ ve $V_{D}=0.03$ olduğu 24 nolu duruma karşılık geldiği görülmüştür (Tablo 1-2).
Tablo 4. Lifli polimer ile sargllı enine ve boyuna donatısız kolon numunelerinin özellikleri

\begin{tabular}{|c|c|c|c|c|c|c|c|}
\hline Makale & $\begin{array}{l}\text { Numune } \\
\text { Adı }\end{array}$ & $\underset{(\mathrm{mm})}{D}$ & $\begin{array}{l}f_{c}^{\prime} \\
(\mathrm{MPa})\end{array}$ & $\begin{array}{l}\mathrm{n} \cdot t_{f} \\
(\mathrm{~mm})\end{array}$ & $\begin{array}{c}E_{f} \\
(\mathrm{GPa})\end{array}$ & $\begin{array}{c}\varepsilon_{f u} \\
(\mathrm{~mm} / \mathrm{mm})\end{array}$ & $\begin{array}{l}P_{u} \\
(\mathrm{kN})\end{array}$ \\
\hline \multirow{27}{*}{$\begin{array}{l}\text { Lin ve } \\
\text { Li [33] }\end{array}$} & A1 & 150 & 17.59 & 0.11 & 232 & 0.018 & 656.65 \\
\hline & A2 & 120 & 17.05 & 0.11 & 232 & 0.018 & 474.60 \\
\hline & A3 & 100 & 17.17 & 0.11 & 232 & 0.018 & 348.15 \\
\hline & A4 & 150 & 17.59 & 0.22 & 232 & 0.018 & 947.63 \\
\hline & A5 & 120 & 17.05 & 0.22 & 232 & 0.018 & 690.55 \\
\hline & A6 & 100 & 17.17 & 0.22 & 232 & 0.018 & 539.94 \\
\hline & A7 & 150 & 17.59 & 0.33 & 232 & 0.018 & 1250.73 \\
\hline & A8 & 120 & 17.05 & 0.33 & 232 & 0.018 & 931.46 \\
\hline & A9 & 100 & 17.17 & 0.33 & 232 & 0.018 & 705.23 \\
\hline & B1 & 150 & 22.31 & 0.11 & 232 & 0.018 & 772.07 \\
\hline & B2 & 120 & 22.29 & 0.11 & 232 & 0.018 & 534.39 \\
\hline & B3 & 100 & 22.60 & 0.11 & 232 & 0.018 & 433.49 \\
\hline & B4 & 150 & 22.31 & 0.22 & 232 & 0.018 & 1053.69 \\
\hline & B5 & 120 & 22.29 & 0.22 & 232 & 0.018 & 836.74 \\
\hline & B6 & 100 & 22.60 & 0.22 & 232 & 0.018 & 618.89 \\
\hline & B7 & 150 & 22.31 & 0.33 & 232 & 0.018 & 1436.00 \\
\hline & B8 & 120 & 22.29 & 0.33 & 232 & 0.018 & 992.02 \\
\hline & B9 & 100 & 22.60 & 0.33 & 232 & 0.018 & 784.10 \\
\hline & C1 & 150 & 24.51 & 0.11 & 232 & 0.018 & 833.42 \\
\hline & C2 & 120 & 24.93 & 0.11 & 232 & 0.018 & 613.69 \\
\hline & C3 & 100 & 24.53 & 0.11 & 232 & 0.018 & 470.46 \\
\hline & C4 & 150 & 24.51 & 0.22 & 232 & 0.018 & 1186.96 \\
\hline & C5 & 120 & 24.93 & 0.22 & 232 & 0.018 & 884.54 \\
\hline & C6 & 100 & 24.53 & 0.22 & 232 & 0.018 & 684.13 \\
\hline & C7 & 150 & 24.51 & 0.33 & 232 & 0.018 & 1508.44 \\
\hline & C8 & 120 & 24.93 & 0.33 & 232 & 0.018 & 1074.21 \\
\hline & C9 & 100 & 24.53 & 0.33 & 232 & 0.018 & 827.24 \\
\hline \multirow{11}{*}{$\begin{array}{l}\text { Karabinis } \\
\text { ve } \\
\text { Rousakis } \\
{[34]}\end{array}$} & C7 & 200 & 47.50 & 0.23 & 240 & 0.0155 & 1617.92 \\
\hline & C8 & 200 & 47.50 & 0.23 & 240 & 0.0155 & 1570.80 \\
\hline & C9 & 200 & 47.50 & 0.23 & 240 & 0.0155 & 1727.88 \\
\hline & C13 & 200 & 47.50 & 0.35 & 240 & 0.0155 & 2104.87 \\
\hline & C14 & 200 & 47.50 & 0.35 & 240 & 0.0155 & 1617.92 \\
\hline & C10 & 200 & 43.50 & 0.23 & 240 & 0.0155 & 1570.80 \\
\hline & C11 & 200 & 43.50 & 0.23 & 240 & 0.0155 & 1523.67 \\
\hline & C12 & 200 & 43.50 & 0.23 & 240 & 0.0155 & 1570.80 \\
\hline & C16 & 200 & 43.50 & 0.35 & 240 & 0.0155 & 1979.20 \\
\hline & C17 & 200 & 43.50 & 0.35 & 240 & 0.0155 & 2120.58 \\
\hline & C18 & 200 & 43.50 & 0.35 & 240 & 0.0155 & 2057.74 \\
\hline
\end{tabular}

Ayrıca Tablo 1 ve 2'de verilen varyasyon katsayılarının herbir durumu için $\phi$ değerinin değișimi donatılı ve donatısız kolonlar için Şekil $3 a$ ve $3 b^{\prime}$ de ayrı ayrı gösterilmiştir. Diğer değişkenlere ilișkin varyasyon katsayıları sabit olmak üzere $f_{c}^{\prime}, E_{f}$ ve $t_{f}$ değişkenlerine ilişkin varyasyon katsayılarının artması, $\phi$ katsayısının azalmasına neden olmaktadır. Bu da varyasyon katsayılarının artması ile, kolonun eksenel yük taşıma kapasitesinin azalması anlamına gelmektedir. İncelenen donatılı ve donatısız kolon numuneleri için belirlenen $\phi$ katsayısı üzerinde diğer değiş̧kenlerle karşılaştırıldığında $f_{c}^{\prime}$ 'nün etkisinin en fazla olduğu görülmüștür.

Şekil 3a'da, donatılı kolonlarda $\phi$ katsayısının ortalama değerinin 24.durum dișında tüm durumlar için yönetmelikte önerilen $\phi=0.65$ değerinden ve Şekil 3b'de ise donatısız kolonlarda tüm durumlar için $\phi=0.60$ değerinden büyük olduğu ve yönetmelik koşullarını sağladığı, diğer bir anlatımla ihtiyatlı yönde oldukları görülmektedir. 
DEÜ FMD 23(69), 995-1004, 2021

Sekil 3c'de ise her bir durum için enine ve boyuna donatılı ve donatısız kolonlar için hesaplanan $\phi$ katsayıları karşılaştırılmıştır. Karşılaștırmada boyuna ve enine donatılı kolonlarda $\phi$ katsayılarının, donatısız kolonlara göre daha büyük olduğu görülmektedir. Donatılı kolonlarda lifli polimerle birlikte enine ve boyuna donatının katkısı, kolonun taşıma gücünü artırdığı için $\phi$ katsayısının değeri donatısız kolona göre daha fazla elde edilmiștir.

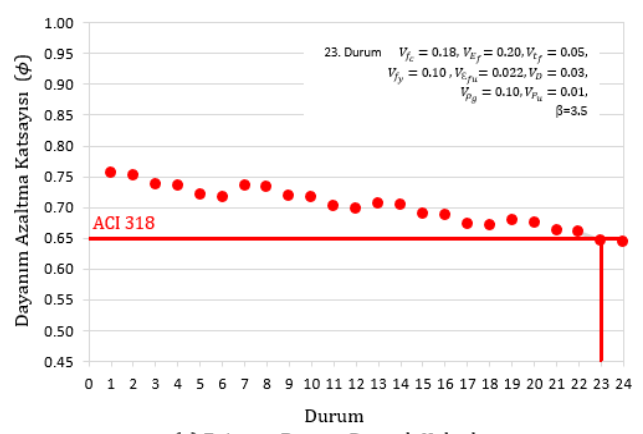

(a) Enine ve Boyuna Donatill Kolonlar

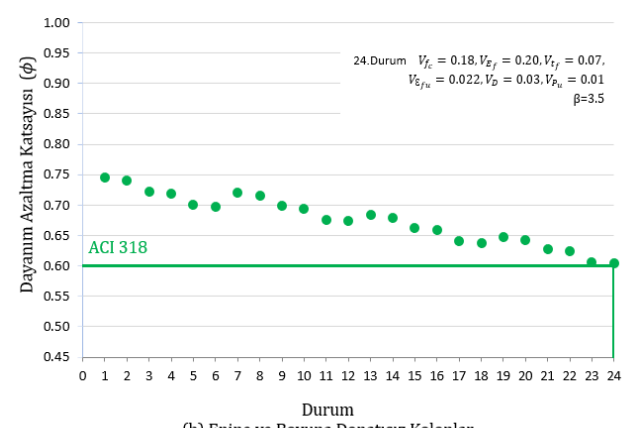

(b) Enine ve Boyuna Donatısız Kolonlar

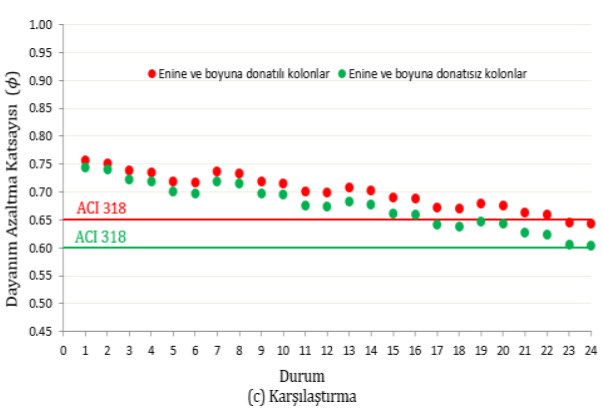

Şekil 3. Lifli polimer ile sargılı kolonlarda $\beta=3.5$ için varyasyon katsayılarının değișiminin $\phi$ üzerindeki etkisi

\section{Rasgele Değişkenler İle $\phi$ Katsayısının Değişimi}

Yapılan hesaplamalar sonucunda incelenen enine ve boyuna donatılı kolonlarda $\beta=3.5$ ve 23 nolu durum için $\phi$ katsayısının $0.607 \sim 0.721$ aralığında değiștiği, numunelerin yaklaşık $\% 62$ 'sinde $\phi$ katsayısının ACI 318-19'da önerilen $\phi=0.65$ değerinden düşük olduğu ve yönetmelik koşullarının sağlanmadığı, \%38'inde büyük olduğu ve koşulların sağlandığı gözlenmiștir.

Benzer şekilde donatısız kolonlarda 24 nolu durum için $\phi$ katsayısının 0.563 0.651 aralığında değiştiği, değişkenlerin yaklaşık $\% 34$ 'ünde $\phi$ katsayısının $\phi=0.60$ değerinden düșük olduğu ve yönetmelik koşullarını sağlamadığı, \%66'sında ise büyük olduğu ve koșulları sağladığı görülmüștür. Deney sonuçlarına göre donatılı kolonlarda $\phi$ katsayısının değișim aralığının donatısız kolona göre daha fazla olduğu anlaşılmaktadır.

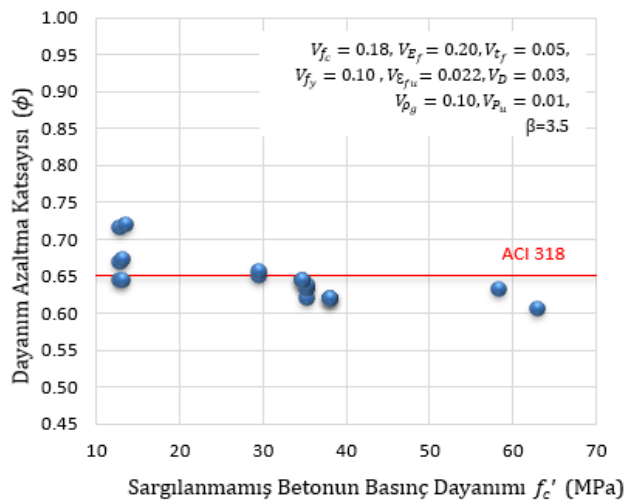

(a)

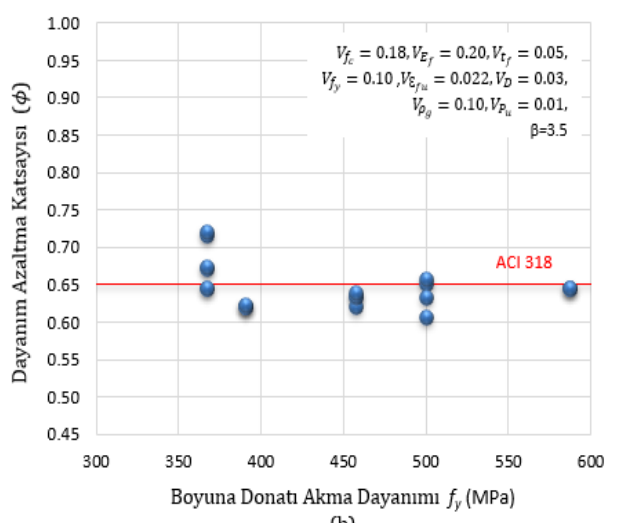

(b) 
DEÜ FMD 23(69), 995-1004, 2021
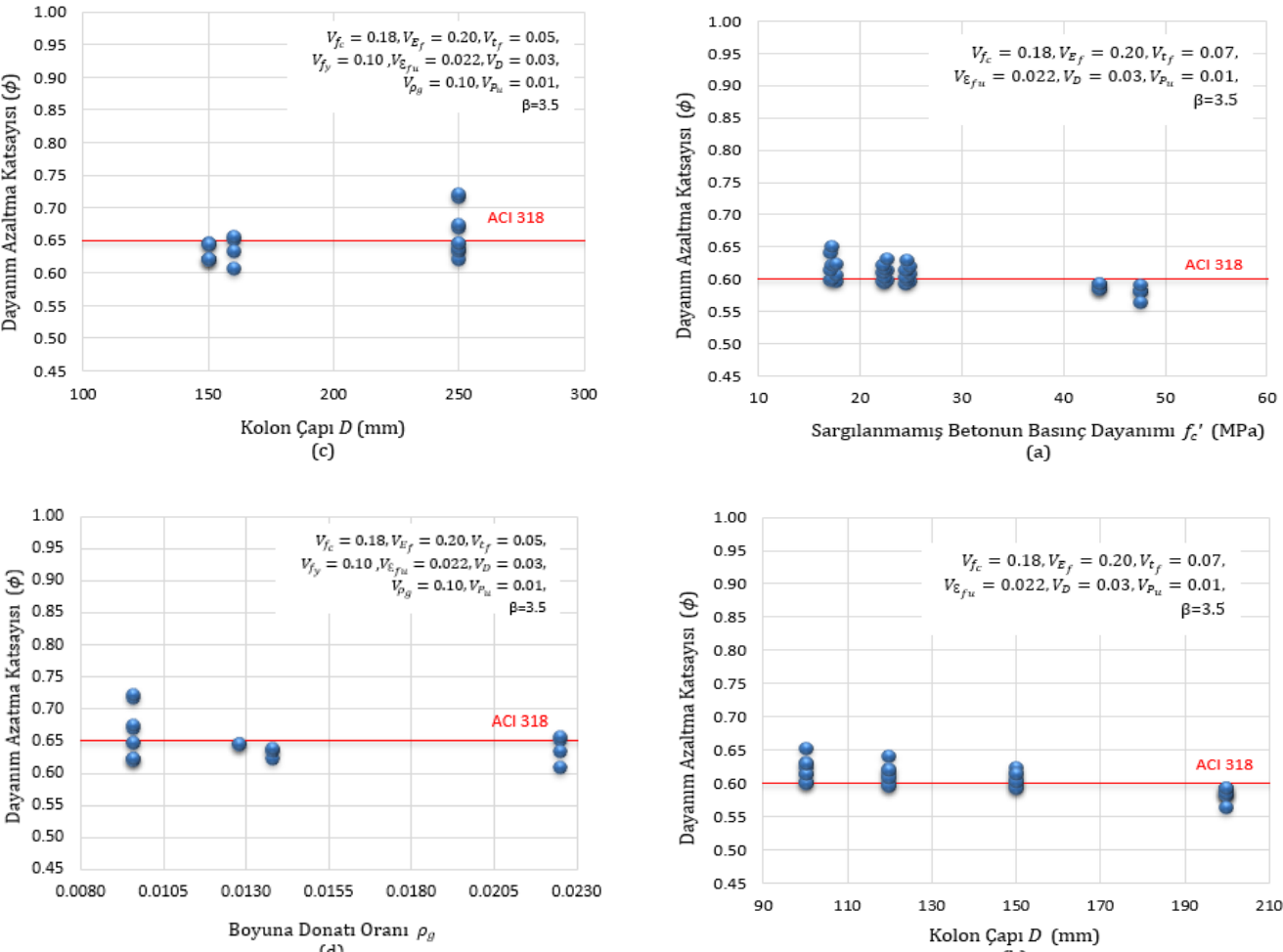

(b)

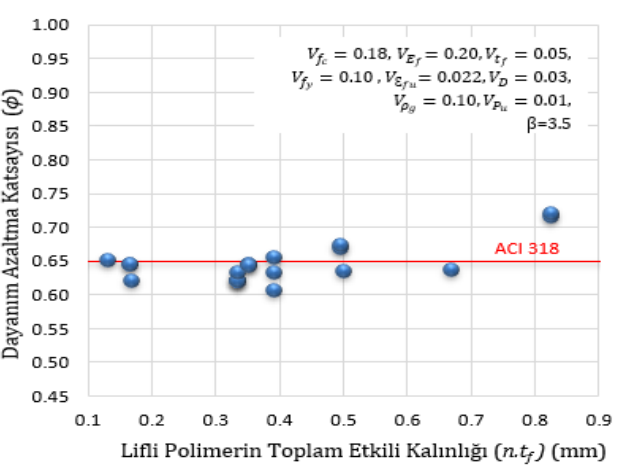

(e)

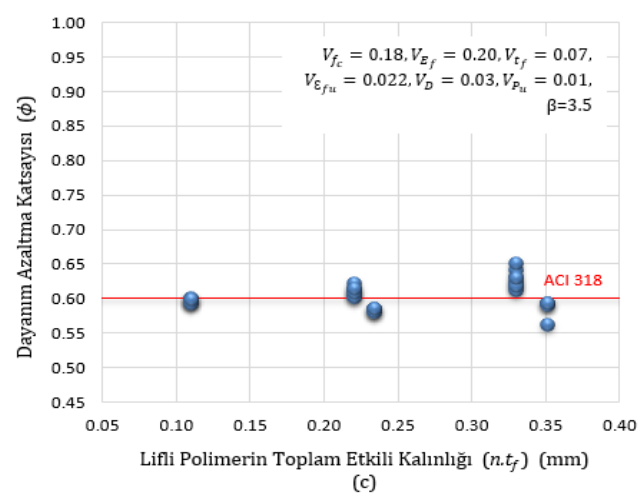

Sekil 4. Lifli polimer ile sargılı enine ve boyuna donatılı kolonlarda $\beta=3.5$ için değișkenlerin $\phi$ üzerindeki etkisi

Şekil 4 ve 5'te donatılı ve donatısız dairesel kolonlarda, $\quad \beta=3.5$ için performans fonksiyonunu olușturan sargılanmamıș betonun basınç dayanımı $f_{c}^{\prime}$, boyuna donatı akma dayanımı $f_{y}$, kolon enkesit çapı $D$, boyuna donatı oranı $\rho_{g}$ ve lifli polimerin toplam etkili sargı kalınlığı n.t $t_{f}$ değişkenlerindeki artışların $\phi$ üzerindeki etkisi gösterilmiştir.

Sekil 5. Lifli polimer ile sargllı enine ve boyuna donatısız kolonlarda $\beta=3.5$ için değişkenlerin $\phi$ üzerindeki etkisi

Şekil 4 ve 5'te görüldüğü gibi incelenen numunelerin sayılarının yetersiz olmasından dolayı donatılı ve donatısız kolonlarda, rasgele değişkenlerin değerlerindeki artışların $\phi$ üzerinde önemli bir değișikliğe neden olmadığı görülmektedir. Değişkenlerin değerlerindeki artışların $\phi$ üzerindeki değişimi hakkında net sonuçlar elde etmek için numunelerin sayılarının artırılması gerekmektedir. 
DEÜ FMD 23(69), 995-1004, 2021

\section{Sonuçlar}

ACI 318-19 yönetmeliğinde eksenel yük etkisindeki kolonların $\phi$ katsayıları, spiral donatılı kolonlar için 0.75 , etriyeli kolonlar için 0.65 ve donatısız kolonlar için 0.60 olarak önerilmiştir. Bu çalışmada spiral etriyeli örnek numuneler göz önüne alınmamıștır. Literatürden sağlanmış lifli polimer ile sargılı boyuna ve enine donatılı (dairesel etriye) ve donatısız eksenel yük etkisindeki dairesel kolonların deney sonuçları kullanılarak ikinci moment yöntemine göre $\phi$ değerleri araştırılmıştır. Çalışmadan elde edilen sonuçlar aşağıda özetlenmiştir.

- Enine ve boyuna donatılı kolonlar için önerilen $\phi=0.65$ değerinin, $\beta=3.5$ için, değişkenlerin varyasyon katsayılarının $V_{f_{c}^{\prime}}=$ $0.18, V_{t_{f}}=0.05, \quad V_{E_{f}}=0.20 \quad V_{\varepsilon_{f u}}=0.022$, $V_{D}=0.03, \quad V_{\rho_{g}}=0.10$ ve $V_{f_{y}}=0.10$ olduğu duruma karşllık geldiği görülmüștür. Varyasyon katsayılarının bu değerlerin altında olması durumunda lifli polimerle sargılı enine ve boyuna donatılı kolonlarda ACI 318-19'da öngörülen $\phi=0.65$ değerinin göz önüne alınması ihtiyatlı olup kolonun güvenilirliğinin artmasına, aksi durumda azalmasina neden olur.

- Enine ve boyuna donatısız kolonlarda ise $\phi=0.60$ değerinin, $\beta=3.5$ için, değișkenlerin varyasyon katsayılarının $V_{f_{c}^{\prime}}=0.18, V_{t_{f}}=$ $0.07, V_{E_{f}}=0.20, V_{\varepsilon_{f u}}=0.022$ ve $V_{D}=0.03$ olduğu duruma karşıllk geldiği görülmüştür. Değișkenlerin varyasyon katsayılarının bu değerlerin altında olması durumunda ACI 318-19'da öngörülen $\phi=0.60$ değerinin göz önüne alınması ihtiyatlı bir yaklașımdır.

- Enine ve boyuna donatının katkısı, kolonun eksenel kuvvet taşıma gücünü artırdığı için $\phi$ katsayısının değeri donatısız kolonlara göre daha büyük elde edilmiștir. Bu nedenle ACI 318-19'da etriyeli kolonlar için önerilen $\phi=0.65$ değeri, donatısız kolonlar için önerilen $\phi=0.60$ değerinden daha büyüktür.

- Tüm deney numunelerinde her bir durum için performans fonksiyonunu oluşturan değişkenlerin varyasyon katsayıları arttıkça $\phi$ katsayısının değeri azalmaktadır. $\mathrm{Bu}$ da değișkenlerin yapısında var olan belirsizliğin artmasının kolonun taşıma gücünü azalttığını göstermektedir.

- Donatılı ve donatısız dairesel kolonlarda, performans fonksiyonunu olușturan değişkenlerin değerlerinin artıșının $\phi$ üzerindeki değișimi hakkında net bir sonuç elde edilebilmesi için incelenen numunelerin saylarının artırılması gerekmektedir.

- ACI 440.2R-17' de lifli polimerle sargilı donatılı ve donatısız dairesel kolonlar için ACI 318'deki katsayılar yerine literatürdeki deney sonuçları kalibre edilerek lifli polimer etkisi de göz önüne alınarak yeni dayanım azaltma katsayıları öngörülebilir.

\section{Kaynakça}

[1] Tarawneh A., Sereen Majdalaweyh S., (2020). Design and reliability analysis of FRP-reinforced concrete columns, Structures, Cilt 28, s.1580-1588. DOI:10.1016/j.istruc.2020.10.009

[2] Xiao Y., Wu H., 2000. Compressive Behavior of Concrete Confined by Carbon Fiber Composite Jackets, Journal of Materials in Civil Engineering, Cilt. 12(2), s. 139-146. DOI: 10.1061/(ASCE)08991561(2000)12:2(139)

[3] Zou Y., Hong H.P., 2008. Reliability Assessment of FRP-Confined Columns Designed for Buildings, Structure and Infrastructure Engineering, Cilt. 7(3), s. 243-258. DOI: 10.1080/15732470802416998

[4] Alqam M., Bennett R.M., Zureick A-H. 2004. Probabilistic Based Design of Concentrically Loaded Fiber-Reinforced Polymeric Compression Members, Journal of Structural Engineering, Cilt. 130(12), s. 1914-1920. DOI: 10.1061/(ASCE)07339445(2004)130:12(1914)

[5] Yingwu Z., Feng X., Lili S. (2013). Reliability Assessments of Concrete Filled FRP Tube Columns, Applied Mechanics and Materials, Cilt 405-408, s.731-734. 10.4028/www.scientific.net/AMM.405-408.731

[6] Mirza S.A. 1996. Reliability-Based Design of Reinforced Concrete Columns, Structural Safety, Cilt. $18(2)$, s. $179-194$. DOI: 10.1016/01674730(96)00010-0

[7] Arslan, G., Alacalı, S. N., Sağıroğlu, A. 2015. The Investigation of the Strength Reduction Factor in Predicting the Shear Strength, Journal of Theoretical and Applied Mechanics (JTAM), Cilt. 53(2), s. 371381. DOI: $10.15632 /$ jtam-pl.53.2.371

[8] Arslan, G., Alacalı, S., Sağıroğlu, A. 2016. Assessing Reduction in Concrete Shear Strength Contribution, Proceedings of the Institution of Civil Engineers Structures and Building, Cilt. 169(4),s. 237-244. DOI: $10.1680 /$ jstbu.14.00102

[9] Alacalı, S., Arslan, G., 2018. Assessment of the Strength Reduction Factor in Predicting the Flexural Strength, Journal of Theoretical and Applied Mechanics, Cilt. 56(4) s. 1043-1053. DOI: 10.15632/jtam-pl.56.4.1043

[10] American Concrete Institute Committee 318 (ACI318), 2005. Building Code Requirements for Structural Concrete (ACI 318-05) and Commentary, Farmington Hills, MI

[11] American Concrete Institute Committee 318 (ACI318), 2014. Building Code Requirements for 
DEÜ FMD 23(69), 995-1004, 2021

Structural Concrete (ACI 318-14) and Commentary, Farmington Hills, MI

[12] American Concrete Institute Committee 318 (ACI318), 2019. Building Code Requirements for Structural Concrete (ACI 318-19) and Commentary, Farmington Hills, MI

[13] American Concrete Institute Committee 440 (440.2R-17), 2017. Guide for the Design and Construction of Externally Bonded FRP Systems for Strengthening Concrete Structures, Farmington Hills, MI

[14] Ang A.H.S., Tang W.H., 1984. Probability Concepts in Engineering Planning and Design, Cilt. 2-Decision, Risk and Reliability, Wiley, NY

[15] Hao H., Li Z.X., Shi Y. 2015. Reliability Analysis of RC Columns and Frame with FRP Strengthening Subjected to Explosive Loads, Journal of Performance of Constructed Facilities, 04015017 DOI: 10.1061/(ASCE)CF.1943-5509.0000748

[16] Ali 0. 2017. Structural Reliability of Biaxial Loaded Short/Slender-Square FRP-Confined RC Columns, Construction and Building Materials, Cilt. 151, s 370-382. DOI: 10.1016/ j.conbuildmat.2017.06.032

[17] Jafari F. 2014. Reliability of FRP Reinforced Concrete Columns, 1. Persian Gulf International Conference on Sustainable Concrete, 17-18 December, Bandar Abbas

[18] Val D., Bljuger F., Yankelevsky D. 1997. Reliability Evaluation in Nonlinear Analysis of Reinforced Concrete Structures, Structural Safety, Cilt. 19, s. 203-217. DOI: $10.1016 / S 0167-4730(96) 00025-2$

[19] Atadero R.A., Karbhari V. M. 2007. Calibration of Resistance Factors for Reliability Based Design of Externally Bonded FRP Composites, Composites: Part B, Cilt. 39, s. 665-679. DOI: 10.1016/j.compositesb.2007.06.004

[20] Hong H.P., Zhou W. 1999. Reliability Evaluation of RC Columns, Journal of Structural Engineering, Cilt. 125(7), s. 784-790. DOI: 10.1061/(ASCE)0733 9445(1999)125:7(784)

[21] Monti G., Santini S. 2002. Reliability Based Calibration of Partial Safety Coefficient for FiberReinforced Plastic, Journal of Composites for Construction, Cilt. 6(3), s. 162-167. DOI: 10.1061/(ASCE)1090-0268(2002)6:3(162)

[22] Kim J.H., Lee S.H., Paik I., Lee H.S. 2015. Reliability Assessment of Reinforced Concrete Columns Based on the P-M Interaction Diagram Using AFOSM, Structural Safety, Cilt. 55, s. 70-79. DOI: 10.1016/j.strusafe.2015.03.003

[23] Val D.V. 2003. Reliability of Fiber-Reinforced Polymer-Confined Reinforced Concrete Columns, Journal of Structural Engineering, Cilt. 129(8), s. 1122-1130. DOI: 10.1061/(ASCE)07339445(2003)129:8(1122)

[24] Taki A., Firouzi A., Mohammadzadeh S. 2018. Life Cycle Reliability Assessment of Reinforced Concrete Beams Shear-Strengthened with Carbon Fiber Reinforced Polymer Strips in Accordance with Fib Bulletin 14, Structural Concrete, Cilt. 19(6), s. 2017 2028. DOI: $10.1002 /$ suco.201700289

[25] Wieghaus K.T., Atadero R.A. 2011. Effect of Existing Structure and FRP Uncertainties on the reliability of FRP-Based Repair, Journal of Composites for
Construction, Cilt. 15(4), s. 635-643. DOI: 10.1061/(ASCE)CC. 1943-5614.0000197

[26] Okeil A.M., El-Tawil S., Shahawy M. 2002. Flexural Reliability of Reinforced Concrete Bridge Girders Strengthened with Carbon Fiber-Reinforced Polymer Laminates, Journal of Bridge Engineering, Cilt. 7(5), s. 290-299. DOI: 10.1061/(ASCE)10840702(2002)7:5(290)

[27] Ruiz S.E., Aguilar J.C. 1994. Reliability of Short and Slender Reinforced-Concrete Columns, Journal of Structural Engineering, Cilt. 120, DOI:10.1061/(ASCE)0733-9445(1994)120:6(1850)

[28] Jiang Y., Yang W. 2012. An Approach Based on Theorem of Total Probability for Reliability Analysis of RC Columns with Random Eccentricity, Structural Safety, Cilt. 41, s. 37-46. DOI: 10.1016/j.strusafe.2012.11.001

[29] Chastre C., Silva M.A.G., 2010. Monotonic Axial Behavior and Modelling of RC Circular Columns Confined with CFRP, Engineering Structures, Cilt. 32, S. 2268-2277. DOI: 10.1016/j.engstruct.2010.04.001

[30] Benzaid R., Mesbah H.A., 2014. The Confinement of Concrete in Compression Using CFRP Compositeseffective Design Equations, Journal of Civil Engineering and Management, Cilt. 20(5), s. 632648. DOI: $10.3846 / 13923730.2013 .801911$

[31] Faustino P., Chastre C., Paula R., 2013. Design Model for Square RC Columns under Compression Confined with CFRP, Composites: Part B, Cilt. 57, s. 187-198. DOI: 10.1016/j.compositesb.2013.09.052

[32] Peker Ö., 2005, Düşük Dayanımlı Betonarme Elemanların CFRP ile Güçlendirilmesi, İstanbul Teknik Üniversitesi, Fen Bilimleri Enstitüsü, Yüksek Lisans Tezi, İstanbul

[33] Lin C.T., Li Y.F., 2003. An Effective Peak Stress Formula for Concrete Confined with Carbon Fiber Reinforced Plastics, Canadian Journal of Civil Engineering, Cilt. 30, s. 882-889. DOI: 10.1139/L03047

[34] Karabinis A.I., Rousakis T.C., 2002. Concrete Confined by FRP Material: a plasticity approach, Engineering Structures, Cilt. 24, s. 923-932. DOI: 10.1016/S0141-0296(02)00011-1 